\title{
WOMEN PERCEPTION ON THE ENVIRONMENTAL EFFECT OF MENSTRUAL PRODUCT WASTE
}

\author{
FatkhuRohmatin, S.K. Habsari \\ Cultural Studies Department, Universitas Sebelas Maret Surakarta, Central Java, Indonesia \\ English Department, Universitas Sebelas Maret Surakarta, Central Java, Indonesia \\ fatkhurohmatin2@student.uns.ac.id, skhabsari@staff.uns.ac.id
}

\begin{abstract}
This research explores women's perception on the environmental effect of menstrual product waste. The types of menstrual products and the reasons why women choose these products are also presented in this study. The qualitative descriptive methods approach was taken, data were collected through a semistructured questionnaire to 40 women from various age and profession backgrounds. The results of this study indicate that the majority of participants agreed and realized that the menstrual products they used (in this case is disposable menstrual pads) also contributed to worsening environmental pollution. But unfortunately, the majority of participants were also still managing their makeshift disposable menstrual pads. However, most participants are still reluctant to switch to menstrual products that are more environmentally friendly due to various reasons.
\end{abstract}

\section{Keyword: Women, Environmental Effect, Menstrual, Waste, Perception}

Penelitian ini mengeksplorasi persepsi wanita tentang efek lingkungan dari sampah produk menstruasi. Jenis-jenis produk menstruasi dan alasan mengapa wanita memilih produk itu juga disajikan dalam penelitian ini. Penelitian ini menggunakan pendekatan metode deskriptif kualitatif, data dikumpulkan melalui kuesioner semiterstruktur terhadap 40 wanita dari berbagai usia dan latar belakang profesi. Hasil penelitian ini menunjukkan bahwa mayoritas partisipan setuju dan menyadari bahwa produk menstruasi yang mereka gunakan (dalam hal ini adalah pembalut menstruasi sekali pakai) juga berkontribusi memperburuk pencemaran lingkungan. Namun sayangnya, sebagian besar peserta masih mengelola sampah produk menstruasi sekali pakai dengan cara yang kurang sesuai. Sementara itu, sebagian besar peserta masih enggan beralih ke produk menstruasi yang lebih ramah lingkungan karena berbagai alasan.

Kata Kunci: Perempuan, Efek Lingkungan, Menstruasi, Sampah, Persepsi

\section{Pendahuluan}

Menstruasi merupakan kebutuhan rutin perempuan setiap bulannya. Berbicara masalah menstruasi, seharusnya tak hanya membahas soal kesehatan wanita, akan tetapi juga kelestarian alam. Fenomena membludaknya sampah pembalut di tempat pembuangan sampah menjadi pemandangan tak asing lagi, terlebih di negara-negara berkembang yang belum mempunyai sistem regulasi dan manajemen pengelolaan sampah yang baik. Ironisnya sampah pembalut sekali pakai pada umumnya membutuhkan kurang lebih 500800 tahun untuk bisa terurai (Potter, 2016). Sementara itu umumnya pembalut sekali pakai mengandung bahan-bahan kimia berbahaya bagi tubuh maupun bagi lingkungan, seperti 
polimer sintetik (Counts et al., 2017; Dey et al., 2016; Kosemund et al., 2009), phthalates (Ishii et al., 2015), dan chlorine (Counts et al., 2017; Koda et al., 2001; Wada et al., 2017). Berapa banyak sampah beracun yang mencemari lingkungan pertahunnya jika dibandingkan dengan jumlah perempuan Indonesia yang mencapai $49,76 \%$ dari Jumlah total penduduk Indonesia tahun 2018 (BPS, 2018) dikalikan 12 kali masa periode menstruasi.

Pada umumnya komponen plastik yang biasa digunakan pada pembalut sekali pakai dan tampon berupa polyethylene. Sementara itu, mayoritas organisme tidak menganggap material tersebut sebagai makanan bagi mereka, karena itu, polyethylene tidak dapat diuraikan (Lapidos, 2007). Sampah pembalut yang tidak dapat diuraikan di tanah akan berakhir di lautan dan berceceran di pinggiran pantai. Sudah banyak kasus penemuan sampah tampon dan pembalut di dalam perut ikan mati (Edwards, 2004). Lusher et al. (2012) menemukan bahwa sebanyak 36, 5\% sampel ikan di saluran air Inggris mengandung microplastik. Microplastik ini jika akhirnya masuk ke tubuh manusia melalui ikan yang dikonsumsinya, tentu akan menimbulkan dampak masalah kesehatan yang serius.

Penelitian terdahulu menyatakan bahwa perempuan adalah kontributor utama serta memainkan peran yang esensial dalam manajemen perlindungan sumber daya alam (Aye, 2018; World Bank, 1991). Bahkan beberapa peneliti menyatakan bahwa perempuan lebih konsen terhadap isu masalah lingkungan jika dibandingkan dengan laki-laki (Davidson and Freudenberg, 1996; Van Liere and Dunlap, 1980; Mohai, 1992). Namun faktanya perempuan juga turut berkontribusi menyumbang sampah terbesar tiap tahunnya. Untuk kebutuhan pribadi perempuan sendiri, berupa sampah menstrual pads atau pembalut, masih banyak yang belum menyadari bahayanya atau belum mengetahui bagaimana cara mengelolanya dengan benar. Rendahnya kesadaran perempuan terhadap manajemen sampah produk menstruasi ini tidak hanya terjadi di Indonesia saja, tetapi juga mayoritas negara berkembang lainnya seperti Afrika (Touré, 2017), India dan Pakistan (Muralidharan, 2018; Windsor, 2017).

Berlandaskan pada fenomena dan paradigma tersebut, penelitian ini hendak mengeksplorasi bagaimana sebenarnya persepsi perempuan Indonesia tentang efek sampah pembalut terhadap lingkungan. Penelitian ini juga memaparkan bagaimana mereka memilih jenis produk menstruasi, bagaimana cara mereka mengelola sampah produk menstruasi, serta opini mereka agar masa period (menstruasi) tetap tertangani dengan baik, tidak mengganggu kesehatan tubuh juga kelestarian lingkungan.

\section{Metodologi}

Penelitian ini menggunakan metode pendekatan kualitatif deskriptif. Data primer diperoleh dengan teknik kuesioner semi terstruktur (a semi-structured questionnaire) terhadap 40 perempuan yang dipilih secara random dari latar belakang usia dan profesi yang berbeda-beda. Hal ini bertujuan untuk mendapatkan variasi jawaban dan melihat adakah perbedaan persepsi yang terjadi dalam memandang masalah sampah produk menstruasi dan pengaruhnya terhadap lingkungan. Untuk tujuan penelitian ini, model kuesioner dibagi menjadi 2 bagian. Bagian yang pertama memuat pertanyaan-pertanyaan tentang identitas singkat partisipan, seperti nama atau inisial, usia, dan profesi. Sementara itu bagian kedua terdiri dari 4 pertanyaan yang berkaitan dengan tema penelitian ini, untuk memahami persepsi perempuan akan dampak sampah produk menstruasi terhadap lingkungan. Pertanyaan-pertanyaan tersebut adalah sebagai berikut: 
1) Peralatan menstruasi apa yang biasa anda pakai?

2) Apakah alasan anda memilih peralatan menstruasi tersebut?

3) (Khusus pengguna pembalut sekali pakai):

a. Bagaimana cara anda mengelola sampah pembalut sekali pakai?

b. Menurut anda, apakah sampah pembalut anda turut berkontribusi menimbulkan masalah lingkungan?

4) Sebagai perempuan, bagaimanakah cara agar masa period kita bias teratasi dengan baik, namun juga tidak menimbulkan masalah lingkungan?

Selain dengan kuesioner, peneliti juga melakukan wawancara singkat secara langsung terhadap beberapa partisipan untuk dapat menggali data-data lebih mendalam. Guna mendukung data primer, penelitian ini juga menggunakan data sekunder yang berasal dari berbagai macam dokumen seperti buku, jurnal, terbitan berkala, dan lainnya. Seluruh data selanjutnya dianalisis dan disajikan secara deskriptif.

\section{Hasil}

\section{Deskripsi Partisipan}

Jumlah partisipan dalam penelitian ini sebanyak 40 perempuan dari jenjang usia yang bervariasi yaitu mulai dari 17 tahun hingga 33 tahun. Jumlah terbanyak berada di usia 18 tahun yaitu 7 partisipan, disusul dengan usia 25 tahun sebanyak 7 partisipan. Berikut ini adalah tabel rinci variasi usia pertisipan yang digunakan dalam penelitian ini:

\begin{tabular}{|l|l|l|}
\hline No & Variasi Usia (tahun) & Jumlah Peserta \\
\hline 1 & 17 & 2 \\
\hline 2 & 18 & 7 \\
\hline 3 & 19 & 1 \\
\hline 4 & 23 & 4 \\
\hline 5 & 24 & 3 \\
\hline 6 & 25 & 7 \\
\hline 7 & 26 & 2 \\
\hline 8 & 27 & 3 \\
\hline 9 & 28 & 1 \\
\hline 10 & 29 & 2 \\
\hline 11 & 30 & 1 \\
\hline 12 & 31 & 1 \\
\hline 13 & 32 & 3 \\
\hline
\end{tabular}




\begin{tabular}{|l|l|l|}
\hline 14 & 33 & 3 \\
\hline \multicolumn{2}{|r|}{ Total } & 40 Partisipan \\
\hline
\end{tabular}

Tabel 1. Tabel variasi usia partisipan

Selain variasi umur, partisipan dalam penelitian ini juga berasal dari latar belakang profesi yang berbeda-beda. Jumlah terbanyak diduduki oleh profesi PNS atau Pegawai Negeri Sipil yaitu sebanyak $42,5 \%$ atau 17 peserta, disusul dengan mahasiswa (25\% /10 partisipan), pelajar (12,5\% /5 partisipan), karyawan swasta (7,5\% /3 partisipan), Ibu rumah tangga ( $5 \%$ / 2 partisipan), sementara itu 3 sisanya yaitu berprofesi sebagai dosen, karyawan lain-lain, dan CPNS. Berikut ini adalah diagram variasi pekerjaan partisipan:

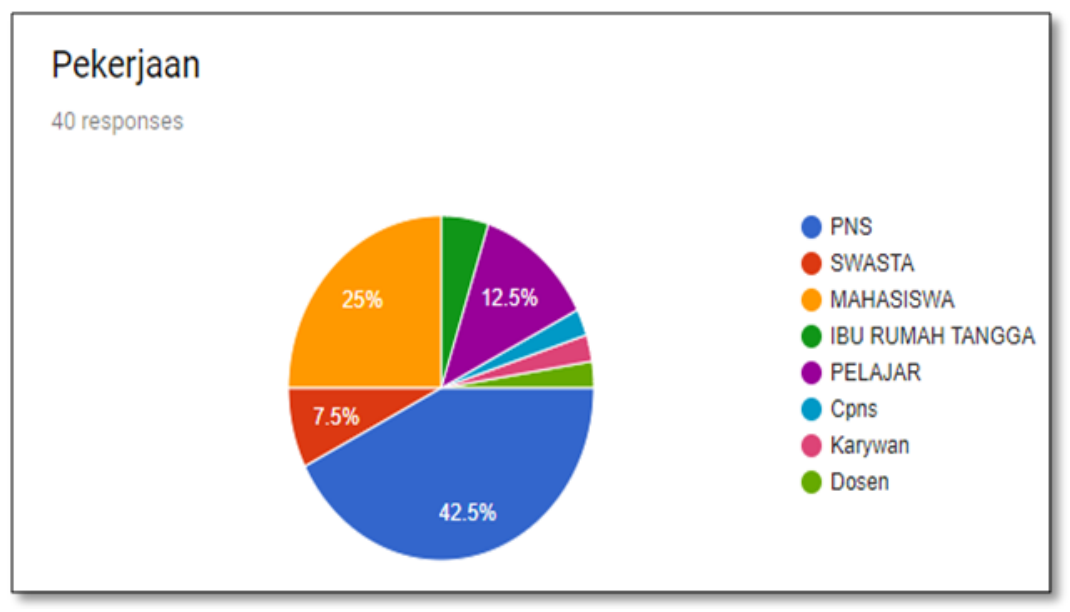

Diagram 1. Variasi pekerjaan partisipan

Mayoritas partisipan tinggal di Ibukota jakarta. Sebagian lainnya berasal dari daerah Jawa Tengah dan Jawa Timur. Untuk partisipan yang tinggal di luar Jakarta, peneliti menggunakan media sosial sebagai sarana komunikasi saat pengambilan kuesioner dan wawancara singkat.

Produk Menstruasi yang Banyak Digunakan

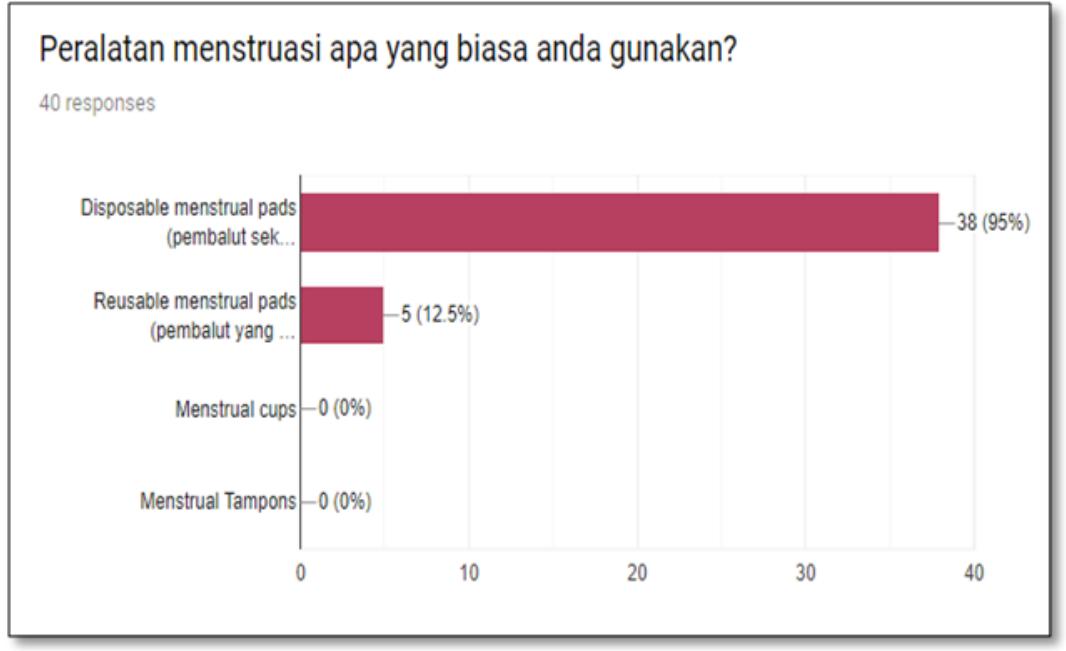

Grafik 1. Grafik penggunaan peralatan menstruasi 
Grafik di atas menggambarkan hasil pengisian kuesioner oleh partisipan mengenai peralatan atau produk menstruasi yang biasa mereka gunakan. Hasilnya 95\% atau 38 partisipan memilih menggunakan disposable menstrual pads (pembalut sekali pakai). Yang memilih menggunakan reusable menstrual pads (pembalut pakai ulang) sebanyak 5 orang atau 12,5\%, namun 3 di antaranya juga memilih disposable menstrual pads. Sementara itu, dari 40 partisipan tidak ada yang memilih menstrual cup maupun tampons. Di Indonesia sendiri pemakaian menstrual cup dan tampons masih dianggap tabu dan bertentangan dengan budaya (CNNIndonesia, 2019).

\section{Alasan Memilih Produk Menstruasi}

Pembalut sekali pakai memang masih menjadi idola bagi perempuan, tidak hanya di Indonesia, tetapi juga di negara lain seperti India (Windsor, 2017) yang mencapai angka 65\% dari jumlah responden dan juga di afrika (Touré, 2017) sebanyak $86,95 \%$ responden. Berikut ini adalah contoh beberapa alasan kenapa partisipan perempuan lebih memilih disposable menstrual pads ( pembalut sekali pakai):

"Lebih praktis dan mudah di dapat"

"Banyak tersedia di pasaran dan murah"

"Lebih nyaman dan mudah cara memakainya"

Sebanyak 22 partisipan memilih pembalut sekali pakai dengan alasan bahwa pembalut itu lebih praktis, nyaman dan mudah diaplikasikan. 7 orang menyatakan bahwa harga pembalut sekali pakai lebih murah jika dibandingkan dengan produk menstruasi jenis lainnya. 12 orang lainnya menyatakan bahwa pembalut sekali pakai lebih mudah didapatkan di pasaran jika dibandingkan dengan produk menstruasi jenis lainnya.

Hasil tersebut menunjukkan bahwa alasan praktis dan mudah didapatkan masih menjadi faktor penting bagi perempuan dalam menentukan jenis peralatan menstruasi. Pernyataan ini senada dengan hasil penelitian terdahulu (Davidson, 2012) yang menyatakan bahwa convenience (nyaman-praktis) dan availability (ketersediaan) dari produk menjadi faktor penting bagi seseorang untuk menentukan pilihan. Meskipun seseorang memiliki banyak pengetahuan dan informasi tentang dampak dari sampah pembalut terhadap lingkungan serta informasi tentang produk lain yang lebih ramah lingkungan, namun jika produk tersebut ketersediaannya masih jarang, maka mereka akan sulit untuk membelinya. Ketersediaan pembalut sekali pakai dengan varian yang begitu banyak di pasaran merupakan salah satu penyebab mayoritas perempuan memilihnya (Scullion, 2017). Media iklan secara tidak langsung juga turut mempengaruhi keputusan perempuan untuk memilih peralatan menstruasi, sementara itu pembalut sekali pakai lebih sering diiklankan baik dalam media cetak maupun media elektronik jika dibandingkan dengan pembalut pakai ulang (Weir, 2015; Scullion, 2017).

Selain itu, dari hasil kuesioner juga menunjukkan bahwa harga juga masih menjadi faktor penentu bagi perempuan dalam memilih jenis peralatan menstruasi. Hasil ini mendukung penelitian terdahulu yang dilakukan oleh Borowski (2011). Bussey (2015) menyatakan bahwa banyak perempuan terstigma untuk tetap memilih produk sekali pakai dengan harga yang murah, meski lebih banyak menghasilkan sampah jika dibandingkan 
dengan pembalut pakai ulang. Dalam jangka waktu yang lama, total harga pembalut pakai ulangpun akhirnya juga lebih murah.

Sementara itu bagi yang memilih reusable menstrual pads (pembalut pakai ulang), mereka memiliki alasan bahwa:

"Sebenarnya lebih aman pakai pembalut pakai ulang. Tetapi ribet kalau untuk di luar rumah. Jadi cuma dipakai kalau untuk diluar rumah saja. menurutku kulit terasa nggak pengap"

"Yang pertama pembalut biasa (pembalut sekali pakai) karena murah. Yang kedua pembalut kain karena lebih aman"

“Lebih ramah lingkungan"

Perempuan yang memilih pembalut pakai ulang selain karena lebih aman bagi kesehatan mereka, juga karena alasan lebih ramah lingkungan. Meskipun mereka memilih reusable menstrual pads, namun menurut mereka, dari segi kepraktisan dan harga, pembalut sekali pakai masih tetap menjadi alternatif utama.

\section{Bagaimana Cara Mengelola Sampah Pembalut Sekali Pakai}

Berkenaan dengan cara mengelola sampah pembalut sekali pakai, sebanyak $89,7 \%$ atau 35 partisipan menjawab dengan cara mencuci, membungkus, dan membuangnya ke tempat sampah. Sementara itu sisanya, 2 partisipan menyatakan langsung membuang ke tempat sampah tanpa mencucinya. Sementara itu partisipan yang notabene berasal dari daerah pedesaan menyatakan bahwa mereka terkadang juga mengubur atau membakar sampah pembalut mereka. Temuan ini senada dengan penelitian terdahulu yang menyatakan bahwa mayoritas perempuan di negara-negara berkembang, khususnya di wilayah urban membuang sampah pembalut mereka ke tempat sampah, dan umumnya bercampur dengan sampah padat lainnya (Ashley et al., 2005), sementara itu perempuan yang tinggal di daerah pedesaan mayoritas mengelola sampah pembalut mereka dengan cara membakar, menimbunnya di dalam tanah atau membuangnya ke lubang kakus (Kaur et al., 2018).

Women Perception in Environmental Effect of Disposable Pads Waste

a. Kontribusi sampah pembalut dalam menimbulkan masalah lingkungan 


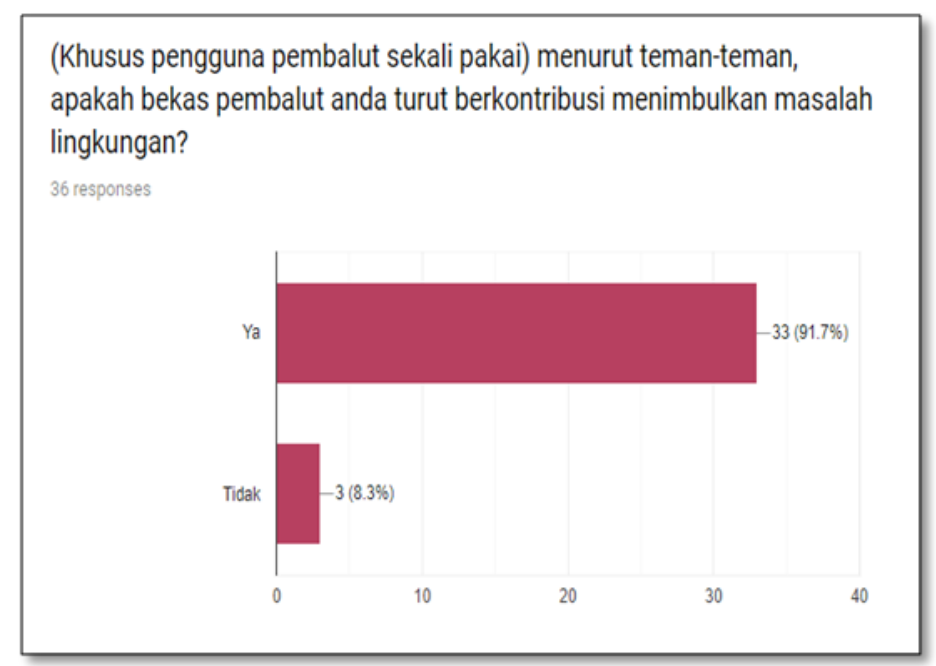

Grafik 2. Persepsi perempuan mengenai kontribusi sampah pembalut terhadap lingkungan

Dari jumlah total 4 partisipan hanya 36 partisipan yang memberikan jawaban (kecuali 4 partisipan yang memilih pembalut pakai ulang). Dari 36 partisipan tersebut, sebanyak $91,7 \%$ (33 orang) menyatakan setuju bahwa sampah pembalut mereka turut berkontribusi dalam menimbulkan masalah lingkungan. Sementara itu hanya 8,3 \% (3 orang) yang menyatakan bahwa sampah pembalut mereka tidak menimbulkan masalah lingkungan.

Dari hasil data di atas dapat di tarik kesimpulan bahwa kesadaran perempuan terhadap lingkungan belum bisa dikatakan menentukan atau berbanding lurus dengan proses pemilihan jenis produk menstruasi yang akan digunakan oleh perempuan tersebut. sebanyak 33 partisipan menyadari bahwa sampah pembalutnya turut berkontribusi menimbulkan masalah lingkungan, meskipun demikian mayoritas mereka masih memilih menggunakan pembalut sekali pakai dan enggan beralih ke produk pembalut yang lebih ramah lingkungan dengan berbagai alasan seperti kepraktisan, kenyamanan, harga, ketersedian, dan sebagainya.

Borowski (2011) dan Weir (2015) menyatakan bahwa tidak ada satupun penelitian yang menyatakan bahwa kesadaran akan dampak sampah menstruasi terhadap lingkungan menjadi faktor penentu ketika seorang wanita memutuskan hendak membeli produk menstruasi. Weir (ibid.) menambahkan bahwa hal ini dikarenakan mayoritas informasi yang diperoleh oleh perempuan akan dampak lingkungan dan informasi dan daya jangkau untuk mendapatkan produk menstruasi yang ramah lingkungan tidak berjalan beriringan.

b. Cara agar masa period perempuan tidak menimbulkan masalah lingkungan

Dari hasil kuesioner ditemukan berbagai variasi jawaban partisipan berkenaan dengan bagaimana cara mereka mengatasi masa period (menstruasi) agar tidak menimbulkan masalah lingkungan. Berikut ini adalah beberapa contoh dari jawaban partisipan:

"Beralih menggunakan pembalut reusable menstrual pads karena lebih aman, mengurangi polusi pada lingkungan, nyaman saat dipakai, dan menjaga kesehatan" 

"Menggunakan menstrual cup atau membuat pembalut sekali pakai dari bahan yang lebih ecofriendly"
"Membakar pembalut yang sudah dicuci dan dibungkus"
"Mencuci bersih, membungkus dan memendamnya di tanah"

Dari 40 respon partisipan, sebanyak 15 partisipan cenderung memilih untuk mencoba beralih ke penggunaan pembalut yang bisa dipakai ulang. Sementara itu sebanyak 8 partisipan lebih memilih tetap menggunakan pembalut sekali pakai namun dengan menyarankan agar bahan yang dipilih untuk membuat pembalut sekali pakai lebih ramah pada lingkungan. Sebanyak 17 partisipan juga lebih memilih menggunakan pembalut sekali pakai dan tetap menggunakan cara konvensional untuk mengelola sampah pembalutnya yaitu dengan dicuci, dibungkus, dibuang ke tempat sampah tertentu, dibakar atau dipendam dalam tanah.

Hasil respon partisipan tersebut menunjukkan bahwa banyak perempuan yang masih memilih untuk tetap menggunakan pembalut sekali pakai, meskipun sudah mengetahui efeknya bagi lingkungan. Salah seorang partisipan menyatakan pendapatnya sebagai berikut:

“... menggunakan pembalut yang ramah lingkungan, akan tetapi praktis dan mudah didapatkan"

Sekali lagi, aspek kepraktisan dan ketersediaan tetap menjadi pertimbangan bagi perempuan untuk beralih ke reusable menstrual pads atau jenis produk pembalut lainnya yang lebih ramah lingkungan (Davidson, 2012; Scullion, 2017). Beberapa partisipan menyatakan bahwa mereka akan beralih dari satu produk ke produk lain biasanya setelah mendapatkan beberapa rekomendasi dari orang-orang yang mereka percaya. Peer opinion dalam situasi tertentu memang bisa menjadi faktor yang kuat untuk menentukan produk yang hendak dipilih oleh seseorang (Peberdy et al., 2019). Koff dan Rierdan (1995) dalam penelitiannya menyatakan bahwa rekomendasi atau arahan seorang ibu sangat penting dan merupakan faktor yang cukup vital dalam proses pembelajaran mengenai produk menstruasi. Sementara itu, Oster dan Thornton (2012) menemukan bahwa rekomendasi seorang teman yang telah menggunakan produk terlebih dahulu juga meningkatkan kepercayaan seseorang untuk beralih menggunakan produk tersebut.

\section{Diskusi}

Kecenderungan perempuan memilih pembalut sekali pakai dengan harga yang cukup murah tanpa mempertimbangkan kandungan komposisi dari pembalut tersebut, serta keengganan perempuan untuk beralih ke produk menstruasi lain yang lebih ramah lingkungan, tentu membawa konsekuensi tersendiri. Berikut ini adalah beberapa konsekuensi dari sampah pembalut sekali pakai jika tidak segera dikelola dengan baik:

1. Semakin menumpuknya sampah pembalut di sekitar bantaran sungai dan pantaipantai. Di tahun 2018 saja, European Commission mengumumkan bahwa sampah produk menstruasi sekali pakai menduduki peringkat no. 5 dengan total 9.493 item sebagai bentuk sampah plastik terbanyak di area pantai Eropa (European Commission, 2018). Keadaan ini tentu saja tidak jauh berbeda dengan fenomena yang terjadi di Indonesia. 
2. Perempuan sering kali membuang sampah produk menstruasinya ke jamban atau toilet. Perusahaan sanitasi di seluruh dunia melaporkan bahwa sampah produk menstruasi menjadi penyebab utama penyumbatan pipa air limbah dengan angka 80-90\% (Womena, 2019). Beberapa penelitian terdahulu juga menyatakan bahwa bahan dasar pembalut sekali pakai yang berupa kapas dengan karakter menyerap cairan dapat mengeblok pipa dan menimbulkan penyumbatan (Sommer et al., 2013; Elledge et al., 2018). Sementara itu meskipun beberapa produk menstruasi dikategorikan produk biogradable dalam sistem pengelolaan sampah, namun seringkali bungkus produk tersebut tetap menggunakan bahan plastik yang tidak bisa diuraikan oleh mikroba (Borowski, 2011; Kjellén et al., 2012; Elledge et al., 2018).

3. Peningkatan pemakaian pembalut sekali pakai ini tentunya juga didukung dengan kenaikan jumlah produksi. Semakin banyak produksi semakin banyak pula bahan produksi yang diperlukan. Womena (2019) menyatakan bahwa 11.000 liter air digunakan untuk menghasilkan kapas $1 \mathrm{~kg}$, sementara itu pestisida yang dibutuhkan sebanyak $7 \%$ sementara dan $16 \%$ obat insektisida dari jumlah pertanian global setiap tahun. Jika demikian berapa banyak zat beracun lagi yang harus dilepaskan ke lingkungan, hanya untuk menghasilkan lagi salah satu sumber pencemaran lingkungan berupa sampah pembalut sekali pakai?.

4. Pengelolaan sampah pembalut dengan cara membakar juga menimbulkan dampak negatif bagi lingkungan dan kesehatan. Gas polusi yang dihasilkan dari pembakaran komponen berbahan plastik dapat mengganggu kesehatan karena kandungan karbon monoksida dan karbon dioksida (Nagy \& Kuti, 2016). Semakin banyak sampah berbahan plastik yang dibakar dengan dalih untuk mengurangi volume sampah, maka akan menimbulkan masalah baru berupa penipisan lapisan ozon karena emizi zat karbondioksida, serta berbagai macam masalah penyakit, seperti kanker karena paparan dioksin jangka panjang dll (Kompas, 2018).

Masih banyak konsekuensi lain dari sampah produk menstruasi sekali pakai baik yang berdampak pada kesehatan manusia maupun bagi lingkungan. Tentunya hal ini menjadi pekerja rumah bersama untuk dicari alternatif penyelesaiannya. Berikut ini beberapa strategi yang bisa diterapkan untuk mengurangi dampak negatif dari sampah produk menstruasi:

1. Mengganti produk menstruasi sekali pakai dengan produk yang bisa dipakai berulang-ulang. Hal ini tentu akan mengurai kuantitas jumlah sampah produk menstruasi yang dibuang ke lingkungan dalam sekali periode menstruasi perempuan.

2. Memilih produk-produk biogradable sehingga bisa diuraikan oleh lingkungan. Tidak membungkusnya dengan plastik saat membuang atau menimbun sampah bekas produk menstruasi.

3. Membuat sendiri peralatan menstruasi dari bahan yang ramah lingkungan dan bisa dipakai ulang.

4. Ketersediaan produk-produk menstruasi yang ramah lingkungan atau yang bisa dipakai ulang lebih ditambahkan, sebaliknya peredaran produk-produk menstruasi sekali pakai dan tidak ramah lingkungan sebaiknya dibatasi.

5. Langkah no. 4 tersebut juga harus dibarengi dengan promosi dan sosialisasi yang memadai dari pihak-pihak terkait agar perempuan lebih mengerti dan menyadari 
akan pentingnya menyeleraskan kebutuhan menstruasi dengan kelestarian lingkungan.

6. Perlu segera adanya regulasi dari pemerintah atau pihak terkait yang mengatur tentang :
a. Jenis bahan yang boleh dipakai untuk membuat produk menstrual pads
b. Aturan promosi dan pemasaran produk menstruasi
c. Manajemen pengelolaan sampah bekas produk menstruasi

Beberapa strategi di atas tidak akan pernah berjalan tanpa adanya kesadaran, sinergi dan kerjasama dari berbagai pihak. Selain itu, untuk menumbuhkan kesadaran masyarakat akan bahaya sampah menstruasi bagi lingkungan juga perlu melibatkan berbagai pihak, mulai dari keluarga, pertemanan, sekolah, masyarakat dan pemerintah.

Ibu menjadi agen utama dalam memberikan pendidikan masalah menstruasi kepada anak perempuannya. Sebagai mana telah disebutkan sebelumnya, Koff dan Rierdan (1995) dalam penelitiannya menyatakan bahwa arahan seorang ibu sangat penting dan merupakan faktor yang cukup vital dalam proses pembelajaran mengenai produk menstruasi. Di sekolah, guru juga bisa berperan menciptakan lingkungan sekolah yang ramah bagi perempuan, khususnya berkaitan dengan masalah menstruasi. Seks edukasi di sekolah membantu seseorang untuk menjaga identitas seksual mereka dari kejahatan seksual, serta memberikan dampingan pengetahuan mengenai perubahan psikologi yang terjadi pada tubuh dan bagaimana menjaga kesehatan personal (Kirby, etal., 2007). Fakta yang ditemukan, seringkali sikap guru tidak menunjukkan dukungan dan kurang menaruh perhatian terhadap masalah menstruasi di sekolah. Padangan budaya, agama, dan lingkungan sosial justru seringkali menjadi penghalang dalam proses seks edukasi (Pokharel, 2006). Menstruasi seringkali menjadi silent issue dalam kehidupan perempuan dikarenakan sikap guru, lingkungan sekolah, serta infrastruktur yang tidak mendukung (Kaur, 2018). Pada akhirnya perempuan memperoleh informasi tentang menstruasi justru dari teman dan internet, yang mana terkadang informasi itu tidak komplet dan multi prespektif.

Membicarakan masalah menstruasi dengan lawan jenis juga masih dianggap sebagai hal yang tabu. Padahal hal ini sebenarnya cukup penting. Dengan mengetahui masalah menstruasi, laki-laki dapat memberikan dukungan dan masukan dalam hal manajemen menstruasi di rumah, di sekolah, di tempat kerja, di masyarakat melalui perannya sebagai seorang suami, ayah, kakak, murid, guru, perancang bangunan dan sarana umum, serta pembuat kebijakan. Pada umumnya, pembuat keputusan rancangan toilet adalah laki-laki, hal ini sering kali menjadi masalah bagi wanita karena tidak banyak desain toilet yang ramah untuk menstruasi terutama saat mengganti peralatan menstruasi, mencuci dan membersihkan bekas menstruasi (O'Reilly dan Louiss, 2014). Dengan mengetahui tentang masalah menstruasi, laki-laki dapat membantu perempuan dalam hal merancang model toilet yang ramah bagi menstruasi, membuat kebijakan-kebijakan terkait dengan menstruasi (misal, kebijakan produksi dan pemasaran produk menstruasi, kebijakan pengelolaan sampah produk menstruasi, dll), dan menciptakan suasana sosial dan lingkungan yang ramah bagi proses menstruasi.

Menstruasi pada hakikatnya tidak hanya menjadi masalah wanita, namun juga lakilaki. Hal ini dikarenakan masalah menstruasi meliputi banyak proses mulai dari pembuatan produk-produk atau alat menstruasi, pemasaran, pembuatan kebijakan, pengelolaan 
sampah produk menstruasi, penciptaan lingkungan yang mendukung proses menstruasi dapat teratasi dengan baik, dan seterusnya. Melihat alur panjang proses menstruasi tersebut, maka dipandang perlu adanya kesadaran dan sinergi antara laki-laki dan perempuan agar proses menstruasi dapat teratasi dengan baik, menguntungkan semua pihak dan tidak menimbulkan masalah lingkungan.

\section{Kesimpulan}

Mayoritas partisipan memilih pembalut sekali pakai sebagai produk atau alat menstruasi mereka dengan alasan kepraktisan, kenyamanan, ketersediaan dan harga. Pada dasarnya perempuan menyadari efek terhadap lingkungan yang disebabkan oleh sampah pembalut sekali pakai. Meski demikian mereka masih enggan berpindah dari penggunaan pembalut sekali pakai dan beralih ke produk menstruasi yang lebih ramah lingkungan. Kesadaran terhadap masalah lingkungan memang seringkali tidak berbanding lurus dengan alasan perempuan dalam memilih produk menstruasi.

Dalam hal manajemen pengelolaan sampah produk menstruasi, mayoritas perempuan juga masih menggunakan cara sekadarnya, seperti mencuci, membungkus, membuangnya ke tempat sampah dan bercampur dengan sampah padat lainnya. Beberapa dari mereka juga ada yang membakar atau menguburnya, pada umumnya hal ini dilakukan oleh partisipan yang berasal dari desa atau daerah yang masih memiliki banyak lahan kosong. Cara-cara pengelolaan tersebut tentunya menimbulkan konsekuensi masalah baru bagi lingkungan, seperti penumpukan sampah pembalut karena tidak dapat diuraikan oleh mikroba, polusi udara oleh gas dioksin karena proses pembakaran produk menstruasi, dll.

Berbagai konsekuensi yang muncul akibat sampah produk menstruasi (yang didominasi pembalut sekali pakai) tentunya menjadi pekerjaan rumah bersama. Perlu adanya strategi untuk menyelesaikan masalah akibat sampah produk menstruasi sekali pakai tersebut, diantaranya yaitu dengan mengganti jenis produk menstruasi sekali pakai yang biasa digunakan dengan produk-produk yang ramah lingkungan serta bisa dipakai ulang, sehingga dapat meminimalisir jumlah sampah yang terbuang ke lingkungan dalam setiap kali siklus menstruasi. Selain itu, juga harus ditetapkan adanya regulasi dan pengawasan ketat terkait produksi dan pemasaran produk-produk menstruasi, serta kebijakan manajemen sampah produk-produk tersebut setelah selesai digunakan.

Keberjalanan strategi-strategi tersebut perlu mendapatkan dukungan dan sinergi dari berbagai pihak, mulai dari perempuan (sebagai individu yang mengalami menstruasi), keluarga, teman, sekolah, masyarakat, lingkungan sosial, agama, dan pemerintah. Kesadaran akan kebutuhan dan masalahnya menstruasi, seharusnya tidak hanya menjadi urusan perempuan, tetapi juga laki-laki, karena ada beberapa sektor yang terkait dengan proses menstruasi, namun kebijakannya di pegang oleh laki-laki. Kesadaran dan sinergi antara laki-laki dan perempuan terkait dengan masalah menstruasi ini diharapkan mampu memberikan solusi yang terbaik agar proses menstruasi dapat teratasi dengan baik, namun di satu sisi juga tidak menimbulkan masalah lingkungan.

\section{Daftar Pustaka}

Ashley, R et al. 2005. Sustainable disposal of domestic sanitary waste. Journal of Environmental Engineering, 131 (2), 206-215. 
Aye, T. T. (2018). The role of rural women in environmental management in Myanmar: A case study of Ngaputaw township. Open Science Journal, 3(1).

Borowski, A. 2011. Are American Women Turning to Reusable and Greener Menstrual Products Due to Health and Environmental Pollution Concerns?. Master Thesis. USA, Rochester: Rochester Institute of Technology.

BPS (Badan Pusat Statistik). 2018. Presentase Penduduk menurut Provinsi dan Jenis Kelamin, 2009-2018. Diakses pada 14 Juli, Jam 15.20 WIB dari https://www.bps.go.id/dynamictable/2018/03/20/1288/persentase-pendudukmenurut-provinsi-dan-jenis-kelamin-2009-2018.html

Bussey, C. 2015. Fluffy vagina blankets: How reusable sanitary pads became a period phenomenon. The Telegraph. Diakses pada 16 Juli, Jam 17. 47 WIB dari https://www.telegraph.co.uk/women/womens-life/11871874/PeriodproductSanitary-pads-you-can-reuse.html/

CNNIndonesia. 2019. Menstrual Cup Masih Terbentur Tabu Nilai Budaya. Diakses pada 16 Juli, Jam 14.06 WIB dari https://www.cnnindonesia.com/gayahidup/20190414233202-255-386356/menstrual-cup-masih-terbentur-tabu-nilaibudaya

Counts, J., et al. 2017. Common diaper ingredient questions: Modern disposable diaper materials are safe and extensively tested. Clin. Pediatr, 56, 23S-27S.

Davidson, A. 2012. Narratives of menstrual product consumption: Convenience, Culture or commoditization? Bull. Sci. Technol. Soc, 32, 56-70.

Davidson, D. J., and W. R. Freudenburg. 1996. Gender and environmental concerns: A review and analysis of available research. Environ. Behav. 28:302-339.

Dey S, et al. 2016. Exposure factor considerations for safety evaluation of modern disposable diapers. Regul. Toxicol. Pharmacol, 81, 183-193.

Dey S., et al. 2016. Modern diaper performance: Construction, materials, and safety review. Int. J. Dermatol, 55 (1), 18-20.

Edwards, R. 2004. Seabirds Filled with Plastic Waste. Diakses pada 18 Juli, Jam 19.53 WIB dari http://www.robedwards.com/2004/12/seabirds-filled.html

Elledge, M., et al. 2018. Menstrual hygiene management and waste disposal in low and middle income countries- a review of the literature. International Journal of Environmental Research and Public Health. 15 (11), p. 2562.

European Commission. 2018. Reducing Marine Litter: Action on single use plastics and fishing gear. Impact Assessment. Di Akses pada 19 Juli, jam 21.06 dari http://ec.europa.eu/environment/circular-economy/pdf/singleuse plastics impact assessment.pdf 
Ishii, S., et al. 2015. Investigation of the amount of transdermal exposure of newborn babies to phthalates in paper diapers and certification of the safety of paper diapers. Regul.Toxicol. Pharmacol, 73, 85-92.

Kaur, R et al. 2018. Menstrual hygiene, management, and waste disposal: Practices and challenges faced by girls/women of developing countries. Hindawi, 1-9.

Kirby D.B., et al. 2007. Sex and HIV education programs: their impact on sexual behaviors of young people throughout the world," Journal of Adolescent Health, 40 (3), 206-217.

Kjellén, M., et al. 2012. Global review of sanitation system trends and interactions with menstrual management practices. Report for the menstrual mangement and sanitation systems project, Stockholm Environment Institute, Sweden, Project Report-2011.

Koda, K., et al. 2001. Oxidative cleavage of lignin aromatics during chlorine bleaching of kraft pulp. J. Wood Sci, 47, 362-367.

Koff, E dan Rierdan, J. Preparing girls for menstruation: recommendations from adolescent girls. Adolescence, 30, 795-811.

Kompas. 2018. Hentikan kebiasaan bakar sampah plastik, bahayanya mengintai anda. Diakses pada 20 Juli, jam 09.00 WIB dari https://sains.kompas.com/read/2018/03/27/190600023/hentikan-kebiasaan-bakarsampah-plastik-bahayanya-mengintai-anda

Kosemund, K., et al. 2009. Safety evaluation of superabsorbent baby diapers. Regul. Toxicol. Pharmacol, 53, 81-89.

Lapidos, J. 2007. Will my plastic bag still be here in 2507? How scientists figure out how long it takes your trash to decompose. Diakses pada 18 Juli, Jam 19.53 WIB dari https://slate.com/news-and-politics/2007/06/do-plasticbags-really-take-500-yearsto-break-down-in-a-landfill.html

Lusher, A. L., et al. 2012. Occurrence of microplastics in the gastrointestinal tract of pelagic and demersal fish from the English channel. Mar. Pollut. Bull, 67, 94-99.

Mohai, P. 1992. Men, women, and the environment: An examination of the gender gap in environmental concern and activism. Society Nat. Resources 5, 1-19.

Muralidharan, A. (2018). Management of Menstrual Waste- Insights from India and Pakistan. India: WaterAid India, Menstrual Health Alliance India.

Nagy, A. \& Kuti, R. 2016. The environmental impact of plastic waste incineration. AARMS, 15 (3), 231-237.

Oster, E dan Thornton. 2012. Determinants of technology adoption: Peer effects in menstrual cup-uptake. J.Eur.Econ.Assoc, 10, 1263-1293.

O'Reilly, K dan Louiss, E. 2014. The toilet tripod: Understanding successful sanitation in rural India. Health \& Place, 29, 43-51. 
Peberdy, E et al. 2019. A study into public awareness of environmental impact of menstrual products and product choice. Sustainability 11, 473.

Pokharel, S., et al. School-based sex education in Western Nepal: Uncomfortable for both teachers and students. Reproductive Health Matters, 14 (28), 156-161.

Potter, A. Menstrual Cups and Period Underwear Review: Welcome to the Undieworld. Choice. 2016.

Scullion, R. 2017. Period poverty: Why no one is talking about eco-friendly solutions. Diakses pada 16 Juli, Jam 17. 25 WIB dari http://www.passblue.com/2017/11/30/periodpoverty-why-no-one-is-talking-about-eco-friendlysolutions/

Sommer, M., et al. 2013. Girls' and women's unmet needs for menstrual hygiene management (MHM): The interactions between $\mathrm{MHM}$ and sanitation systems in low income countries. Journal of Water Sanitaiton and Hygiene for Development, 3(3), 283-297.

Touré, B. C. (2017). Knowledge, attitudes and practices pertaining to menstrual hygiene management in suburban areas in the Dakar region. Afrika: Speak Up Africa's Report.

Van Liere, K. D., and R. E. Dunlap. 1980. The social bases of environmental concern: A review of hypotheses, explanations and empirical evidence. The Public Opinion Quarterly, 44 (2), 181-197.

Wada, T., et al. 2017. Proposal of a flow scheme for the chemical-form-based quantitative analysis of chlorine compounds in pulp for sanitary products and verification of safety. Regul. Toxicol. Pharmacol, 91, 109-116.

Weir, C. (2015). In the red: A private economic cost and qualitative analysis of environmental and health implications for five menstrual products. Diakses pada 16 $\begin{array}{lllll}\text { Juli, Jam } & 17 & 37 & \text { WIB } & \text { dari }\end{array}$ https://cdn.dal.ca/content/dam/dalhousie/pdf/science/environmental-scienceprogram/Honours\%20Theses/2015/ThesisWeir.pdf

Windsor, C. (2017). Periods, Perceptions, Practices: A Participatory Inquiry into Women's Experiences of Menstruation and Menstrual Hygiene in Jhansi, India. India: Pria, Knowledge, Voice, Democracy.

Womena. 2019. What is the environmental impact of menstrual products?. Diakses pada 20 Juli, jam 14.00 WIB dari http://womena.dk/what-is-the-environmental-impact-ofmenstrual-products/

World Bank. (1991). Women and development in Malawi: constraints and actions. Washington DC: World Bank. 